\title{
Comparing economic development corporation and internal department models: Service delivery in Southern Ontario ${ }^{1}$
}

\author{
Paul Parker, Evonne Donaher
}

An increasing number of communities are investing in formal economic development departments or organizations, leading to debate over where the effort should be housed. The purpose of this study is to undertake a systematic investigation of two models of economic development service delivery: internal municipal department model and external corporation model. Both qualitative and quantitative methods are used, including in-depth interviews with economic development practitioners and empirical analysis.

The findings show that senior economic development professionals generally believe that the service delivery model matters, but there is disagreement on what operational areas are affected and how. Empirical analysis of the program areas and financial and staffing resources shows substantial overlap between internal and external organizations. However, comparing experiences in partnerships, governance, decision-making, and accountability indicates that there are differences between the two models.

The research also indicates that there are factors beyond the model that may be more influential: the size of the organization or where the decision-making power lies for the given situation may influence the speed of decision-making more than the model. Participants also identified the important role of leadership and people in creating a successful economic development organization.

Key words: Economic development organizations, corporations, departments, service delivery models

\section{Introduction}

The field of economic development is growing. With more communities investing in formal organizations, the debate over where the economic development effort should be housed continues. The purpose of this study is to undertake a systematic investigation of alternative models of economic development service delivery. Two main models are studied: a department or committee within a municipality ("internal municipal department model") and an agency or corporation with a separate board ("external corporation model").

\footnotetext{
${ }^{1}$ Based on the report: Economic development organizations and service delivery models, by Paul Parker and Evonne Donaher, School of Environment, Enterprise \& Development, University of Waterloo, Waterloo, ON. 2012.
} 
The objectives of the study are to perform an empirical analysis comparing the case study organizations using various indicators and to understand differences between the two models based on the experience of senior economic development professionals. This research draws from the case study area of southern Ontario, where a range of organizations in the two models is available for comparison. The study uses both qualitative and quantitative methods, employing in-depth interviews with economic development practitioners and analysis of organization websites, budgets, and reports.

The findings provide insight to the question of which service delivery model may be most appropriate for an economic development organization. The study explores key issues of organizational design and examines the views of senior economic development practitioners in the context of empirical indicators and past research on the subject of service delivery models.

\section{Literature Review}

The economic development profession has grown to include a variety of functions and services, requiring delivery models that provide strong connections to the municipal council and administration as well as other levels of government, institutions and the business community (Thompson, 2010; UBCM, 2010). With the numerous networks and relationships required of the profession, there is often debate over where the economic development effort should be housed (Bowen et al., 1991; Rubin, 1988). This literature review is divided into two sections. The first explores the general types of economic development organizations while the second highlights issues related to service delivery models in Canada.

\subsection{A typology of economic development organizations}

In their book, Planning Local Economic Development, Blakely and Leigh (2009) present a typology of development organizations that includes three models:

1. Economic development as units of local government ("internal" municipal department)

2. Economic development corporations ("external" corporation)

3. Independent private development agencies

The first and second models are most prevalent in Southern Ontario and are, therefore, the focus of this study (Thompson, 2010; Blais and Redden, 2009). It is recognized that "these organizational approaches are seldom observed in their pure form" (Blakely \& Leigh, 2009, p. 405). While many organizations exist in "hybrid" forms, there is value in examining the types of service delivery models as "archetypes" to explore the main differences, advantages and disadvantages.

The internal economic development department as a business unit of local government, sometimes referred to as the "in-house model", exists in different forms, depending the size of 
the community, the municipal status (upper, single or lower tier), historical context, and other factors. In some communities, economic development is a sub-department or division within a larger planning, community services, or similar department. In smaller (particularly rural) communities, there may be a single person who manages the municipality's economic development activities (Douglas \& Chadwick, 2003; UBCM, 2010). In all cases, the internal economic development department reports, sometimes through a chain of command, to the Chief Administrative Officer and is formally governed by the elected Council and Mayor. There are also instances of "less formal [in-house] delivery mechanisms, such as the use of voluntary committees, the services of a planning department or other related department, and/or the use of a staff member with primary responsibilities other than economic development" (UBCM, 2010, p. 15).

The advantages of this model can include internal alignment with council and closer communication, collaboration and coordination with other municipal departments; integration of administration with municipality; potential for more sustainable wages and benefits; and less expectation for sourcing additional funding (Thompson, 2010; Myhal, 1994; Blakely \& Leigh, 2009). There is a perception of greater accountability and less opportunity for decisions that primarily benefit certain businesses as they might with a board of directors (Myhal, 1994; Bowen et al., 1991; Rubin, 1988). The municipal role in economic development also includes the important and undervalued contribution of core service delivery such as infrastructure and community planning, which can be facilitated by an internal economic development department (UBCM, 2010).

The economic development corporation, sometimes referred to as not-for-profit or "joint power" organizations or public-private partnerships, is another common service delivery model (Blakely \& Leigh, 2009; Rubin, 1986; Thompson, 2010). Given the numerous rationales for and criticisms against corporations, agencies, boards and commissions, Siegel (1994) suggests that there are four situations for which the use of these types of organizations is appropriate: 1) the service area is multi-jurisdictional, 2) the issue is intergovernmental, 3) flexibility in service delivery or organizational structure is required, or 4) the function benefits from arm's length delivery.

Multi-jurisdictional agencies may be established when the optimal service delivery area for a function crosses several municipal boundaries. Given the increasing emphasis on regional cooperation and collaboration for economic development, this rationale may be increasingly used for separate corporations that span several municipalities.

The intergovernmental policy rationale refers to issues that require the involvement of several levels of government. Given the use of multiple tiers in Ontario, this argument may apply to economic development organizations and would likely be used in similar situations as the multijurisdictional service area rationale. 
Flexibility is an issue because the large, complex structure of government has lead to great emphasis on procedural accountability, and "made it difficult for governments to be innovative and to respond quickly to opportunities and threats" (Siegel, 1994, p. 90). While the optimal response is to remove the inflexibility within government, external agencies are sometimes created to allow for greater flexibility. There is, however, a risk that external agencies become so driven by alternate goals that they forget their service is ultimately provided for the benefits of the community as a whole.

The need for arm's length decision making is a rationale used when there is a need to separate decision-making from the political process. Examples include the avoiding the exercise of a state's coercive powers, or regulatory decisions that may demonstrate favouritism or abuse of power if there is political involvement (Siegel 1994).

Elements of each of these four criteria (multi-jurisdictional, intergovernmental, flexible and arm's length) can be considered when deciding whether economic development services should be provided internally or externally.

\subsection{Economic development service delivery models}

Thompson (2010) presents the most relevant research on the subject of service delivery models for local economic development in Ontario, focusing on single and lower-tier municipalities with over 15,000 in population. His study includes a comparison of the advantages of internal and external models, informed by a survey of economic development practitioners throughout Ontario, and an analysis of the adoption of each model by economic development organizations over time. The key findings from Thompson's research are as follows:

- Instances of the corporate model in Ontario declined from nine in 1999 to eight in 2009. Only six of these organizations consistently operated externally; others changed to or from the internal municipal model. In contrast, 52 internal economic development municipal departments (lower and single tier) existed in 1999, increasing to 65 in 2009.

- Advantages to each model are identified. Both models have the potential for business community engagement through advisory committees; roles and responsibilities in the decision-making process must be defined through clear terms of reference.

- A key factor in identifying the optimal model is the governance and decision-making process. Should the municipality be directly involved or would a board of directors be more appropriate? Accountability is a key consideration, particularly with the corporation model.

- Neither model was determined to be superior as the importance of context and community characteristics and priorities is recognized.

Blais and Redden (2009) present the results of a study by Millier Dickinson Blais on Ontario upper-tier municipalities with 50,000+ population that contrast with Thompson's results. In 
2008, service delivery models in these larger communities were evenly split, with 13 internal, 12 external, and three "combined" organizations, suggesting that external organizations are more common and perhaps better suited to larger communities. Blais and Redden also suggest, "the decision to go internal or external is really a local one" $(2009$, p. 20$)$.

The emphasis on local context is echoed by the Union of British Columbia Municipalities (UBCM, 2010), which released a comprehensive report on economic development with a large focus on service delivery models. This research included a survey of 124 local governments in British Columbia (ranging from less than 5,000 population to greater than 50,000) on method of economic development service delivery, staffing resources, and perceived effectiveness of chosen delivery model, among other topics. There are a number of notable findings from the UBCM (2010) report:

- The majority of local governments with an economic development function operate an "in-house" model, with some combination of a formal department and less formal mechanisms. There is a move to more blended models demonstrating elements of both the in-house and arms-length models.

- The survey asked respondents to identify how effective local governments felt their service delivery model to be. In-house models were generally considered more effective than arms-length models, but lack of response from corporations makes comparison a challenge. Only $21 \%$ of all respondents felt their model is "highly effective," suggesting improvements can be made across the field. Eight criteria influencing the effectiveness of delivery models were:

- Amount of staff

- Quality of staff

- Financial commitment

- Contact with stakeholders

- Support of council

- Support of community

- Evidence of partnerships

- Presence of a regional approach

- The report identifies six main factors for consideration when determining which service delivery model may be most suitable and offers a comparison based on these factors:

- Operational costs and access to external funding

- Relationship with business community

○ Relationship with local government

- Administration and regulation

○ Co-location with other agencies 
○ "Deal-making" and the provision of incentives

\subsubsection{Form Follows Function}

Like much of the research on the topic, the UBCM (2010) concludes that one size does not fit all. There is acknowledgement by the Economic Developers Association of Canada (as cited in Redden, 2010, p. 37) that "there is no one right way to organize a local economic development program. One community's model of practice may not work elsewhere." The literature review reveals that identifying the optimal delivery model should depend, in large part, on understanding the goals and priorities of an organization, potential partnerships, and community characteristics (Blais \& Redden, 2009; Blakely \& Leigh, 2009; Thompson, 2010; UBCM, 2010). As Richmond and Siegel (1994, p. 112) summarize, "The key to good organizational design is to fit the organizational structure to the needs of the particular situation at hand. Too often, organizational design decisions are made on the basis of over-reaction, rhetoric, historical precedent, or fad."

\section{Methodology}

This study uses both qualitative and quantitative methods. In-depth interviews were conducted with economic development practitioners from the case study organizations. These semistructured interviews aimed to gain insights into the organizations' mandates, structures, governance, funding, and processes as well as the practitioners' experiences with perceptions of alternative service delivery models. The interviews were followed with short emailed surveys on performance indicators. In addition, organization websites, budgets, and reports were analyzed. The research was conducted from January to June 2012. All research instruments used in this study were reviewed and approved by the University of Waterloo's Office of Research Ethics.

The selected economic development organizations were located in the province of Ontario to reduce the number of factors beyond the service delivery model, such as differing national or provincial regulations, that might influence the comparison. Of the 12 organizations invited to participate, six internal municipal departments and four external corporations were interviewed (Table 1). One of the external corporations was in the process of transitioning to an internal business unit, so the interview was based on their external corporation experience rather than speculating about future experience under the internal model. Another economic development office had been external until a few years ago, but the recent internal municipal experience (2009-2012) was used as the basis for their responses.

The individuals interviewed in both models have a range of previous experience in economic development organizations as well as the private sector and other levels of government (Table 2). These backgrounds provide a wealth of knowledge and experience for their input to the study. 
Table 1: Participating economic development organizations, service delivery model represented, municipal status of jurisdiction(s), population served, and population density

\begin{tabular}{|l|l|l|l|l|}
\hline Organization & Model & Municipal Status & Population 2011 & $\begin{array}{l}\text { Density Pop/sq } \\
\mathrm{km}\end{array}$ \\
\hline I1 & Internal & Single Tier & 103,671 & 42 \\
\hline I2 & Internal & Single Tier & 73,214 & 24 \\
\hline I3 & Internal & Upper Tier & 73,000 & 25 \\
\hline I4 & Internal & Single Tier & 63,175 & 39 \\
\hline I5 & Internal & Upper Tier & 37,571 & 34 \\
\hline I6 & Internal & Lower Tier & 18,424 & 151 \\
\hline E1 & External & Multiple Tiers & 431,346 & 233 \\
\hline E2 & External & Multiple Tiers & 134,933 & 35 \\
\hline E3 & External & Multiple Tiers & 126,199 & 42 \\
\hline E4 & External & Multiple Tiers & 388,782 & 210 \\
\hline Soure: & & &
\end{tabular}

Source: Ontario Ministry of Municipal Affairs and Housing; Statistics Canada, Census of Population, 2011.

Table 2: Number of participants by model with previous experience in other organizations

\begin{tabular}{|l|l|l|}
\hline Type of Prior Experience & $\begin{array}{l}\text { Internal Municipal } \\
\text { Department }\end{array}$ & External Corporation \\
\cline { 2 - 3 } & 6 in total & 4 in total \\
\hline Internal Municipal Department & 3 & 3 \\
\hline $\begin{array}{l}\text { External Economic Development } \\
\text { Corporation }\end{array}$ & 4 & 1 \\
\hline Business & 5 & 2 \\
\hline Government & 2 & 1 \\
\hline
\end{tabular}

Source: Participant interviews; personal communications.

\section{Findings}

\subsection{Organizational mandate \& scope}

There is a wide variety in the mandate and functional program areas of the organizations interviewed. The range of functions and projects undertaken is important when considering aspects of the organization like budget, structure, and partnerships. When asked to identify their organization's main programs, participants identified the following functions and program areas:

- Agriculture \& local food

- Business retention and expansion

- Community capacity
- Marketing

- Newcomer attraction

- Sector \& cluster development 
- Heritage and culture

- Human capital

- Innovation and knowledge economy

- Investment attraction
- Small business and entrepreneurship

- Tourism

- Workforce development

All of these programs represent varying degrees of staffing requirements, investment, partnership, and stakeholder engagement. There are, however, three functions that appear to be significant distinctions between the scope, size, and resources of the participating organizations: tourism, business development/entrepreneurship, and innovation functions.

Tourism services are often, but not always, affiliated with economic development organizations. Six of the 10 participating organizations have a significant tourism program as a key pillar of their organizational mandate. Most of these programs revolve around tourism marketing efforts, some of which are delivered through regional partnerships involving shared costs. There are also instances of visitor information centres managed by the economic development office, requiring an additional set of staff and resources.

All of the participating organizations provide business development support with varying degrees of formality. Of the 10 organizations interviewed, five offer formal business advisory services in the form of a Small Business Enterprise Centre (SBEC), in partnership with the Ontario Ministry of Economic Development and Innovation (MEDI). Included in these five organizations are three of the external corporations and two of the single tier internal departments.

In the case of the external corporation in the $\mathrm{ED}+\mathrm{SBC}+$ Tourism category, a significant research-innovation-commercialization centre function provides additional opportunities for funding and increases demand on organizational resources. This corporation appears as an outlier in many of the figures in section 0 and, given the small sample size, influences the average value calculations. One municipal department also provides "innovation" services through a dedicated staff member, but does not appear to have a significantly altered budget as a result.

Table 3: Scope of main activities and programs of participating organizations

\begin{tabular}{|l|c|c|c|}
\cline { 2 - 4 } \multicolumn{1}{c|}{} & $\begin{array}{c}\text { Economic } \\
\text { Development }\end{array}$ & Tourism* & \begin{tabular}{c} 
Small Business $_{\text {Centre }^{\dagger}}$ \\
\hline \multirow{3}{*}{$\begin{array}{l}\text { Internal municipal } \\
\text { departments }\end{array}$}
\end{tabular} \\
\cline { 2 - 4 } & $\checkmark$ & & \\
\cline { 2 - 4 } & $\checkmark$ & $\checkmark$ & \\
\cline { 2 - 4 } & $\checkmark$ & $\checkmark$ & $\checkmark$ \\
\hline
\end{tabular}




\begin{tabular}{|l|c|c|c|}
\hline & $\boldsymbol{V}$ & $\boldsymbol{V}$ & $\boldsymbol{V}$ \\
\hline \multirow{3}{*}{$\begin{array}{l}\text { External } \\
\text { corporations }\end{array}$} & $\boldsymbol{V}$ & & $\boldsymbol{V}$ \\
\cline { 2 - 4 } & $\boldsymbol{V}$ & $\boldsymbol{V}$ & $\boldsymbol{V}$ \\
\cline { 2 - 4 } & $\boldsymbol{V}$ & $\boldsymbol{V}$ & $\boldsymbol{V}$ \\
\hline
\end{tabular}

* Some include visitor information centres or pavilions that involve weekend staffing.

${ }^{\dagger}$ These organizations have MEDI-affiliated small business centres. All organizations interviewed have some form of business services, whether formal or informal.

Source: Participant interviews

Four categories of organizational scope result:

- $\quad$ ED only = economic development services only

- $\mathbf{E D}+\mathbf{S B C}=$ economic development services and small business centre (also referred to as "business enterprise centre" or "business advisory centre")

- $\mathbf{E D}+$ Tourism $=$ economic development services and some form of tourism program

- $\mathbf{E D}+\mathbf{S B C}+$ Tourism $=$ full service organization including economic development and tourism services and a small business centre

\subsection{Finances}

Funding, budgets and other financial considerations are a major concern for all organizations. Finance-related issues were identified as advantages of both models. Nearly all respondents in both models specifically identified insufficient or limited resources as a challenge for their organization. Some indicated that even when they have resources it is not simply aligned with expectations, mandate, and strategic plan objectives.

The following analysis explores key elements of the participating economic development organizations' finances. The following terminology is used:

- Core or operating budget refers to the base budget of the organization or department received from its main sources of funding on an annual basis.

- Total budget refers to the overall budget of the organization in a given year including its core budget and any additional project budgets. This amount varies year over year.

- Municipal funding refers to funding received by the organization or department from the municipalities in its service delivery area.

- Non-municipal, "external" or "outside" funding refers to funding received by the organization or department from any source beyond municipal funding, including other levels of government, the private sector, and various other organizations. 


\subsubsection{Budgets}

Participants were asked to identify their organization or department's core and total budgets for a recent sample year. The annual core operating budgets identified by the participating organizations ranged from $\$ 155,000$ to $\$ 2.2$ million. The total budgets ranged from $\$ 200,000$ to $\$ 4.4$ million. Given variation in the population size served by the participating organizations, an analysis of the budget per capita was completed. The average core budget per capita for internal organizations was $\$ 13$ and $\$ 8$ for external organizations. The average total budget per capita was $\$ 15$ for internal organizations and $\$ 14$ for external organizations. However, the sample size is too small to draw any firm conclusions on the effect of service delivery model on budgets.

Error! Reference source not found. and Error! Reference source not found. suggest that the scope of the organization's mandate may be a stronger indicator of budget per capita than the organizational model. There is no clear pattern of one service delivery model generating a larger budget. Instead, the larger per capita budgets were found in organizations that included both economic development and tourism mandates.

Figure 1: Annual core operating budget per capita by organizational scope

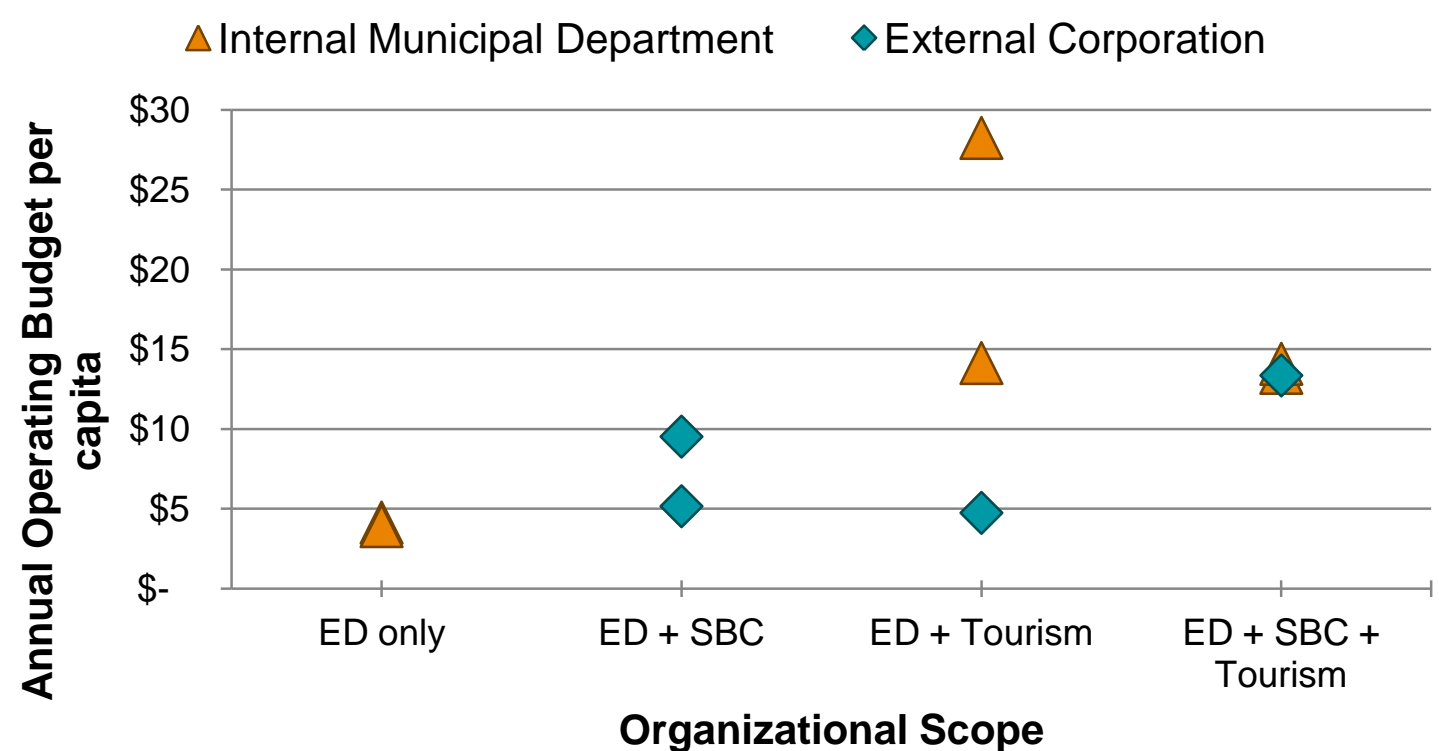

Sources: Participant interviews; Statistics Canada, Census of Population, 2011 [Custom tabulations]. 
Figure 2: Total budget per capita by organizational scope

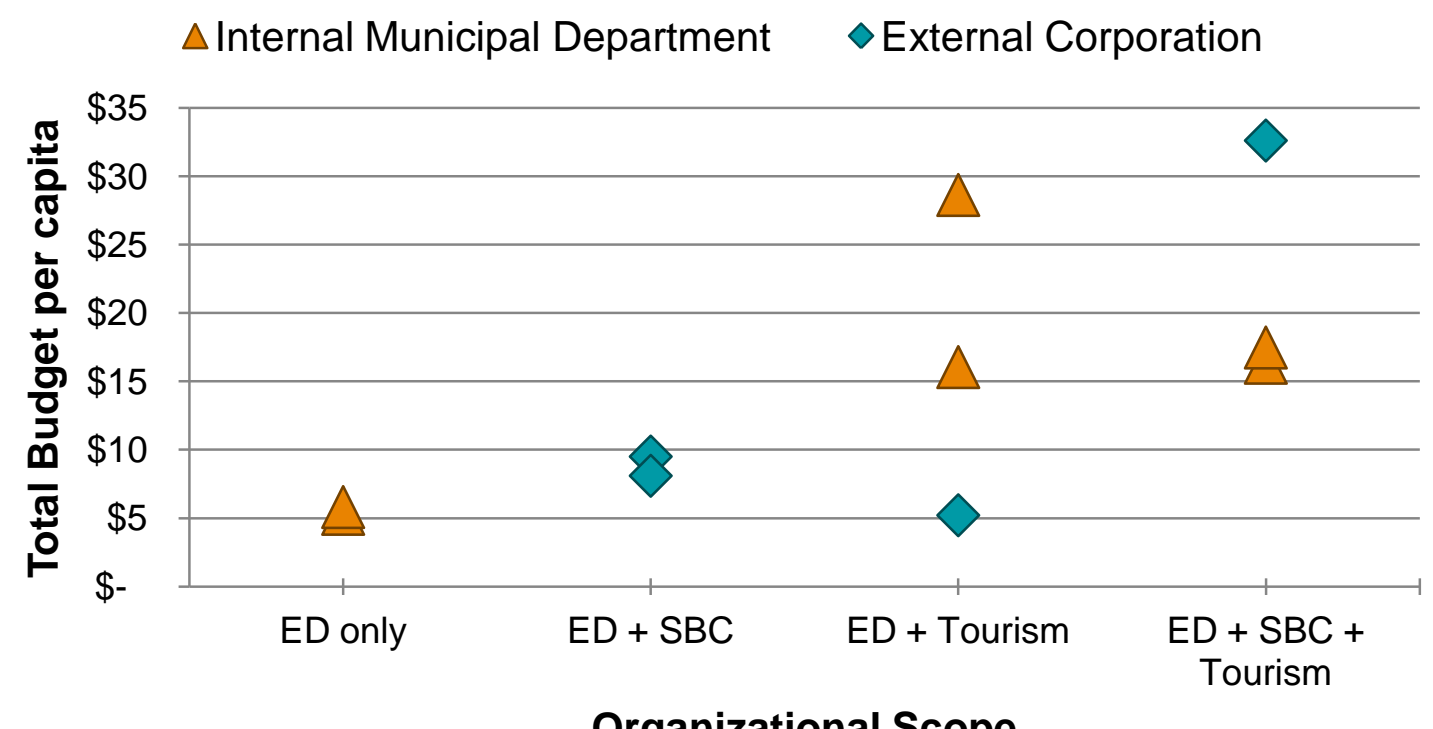

Sources: Participant interviews; Statistics Canada, Census of Population, 2011 [Custom tabulations].

\subsubsection{Sources of Funding}

A variety of funding sources are accessed by the organizations interviewed. Sources include all levels of government, the private sector, one case of CFDC funding and one case of funding from universities, colleges and other institutions. Table 4 shows the number of organizations of each service delivery model that identified the funding source listed during the interview or in a budget or other report. For example, three municipal departments and four corporations indicated they have received funding from the federal government.

Table 4: Number of organizations by service delivery model identifying funding sources.

\begin{tabular}{|l|c|c|}
\hline Funding Source & $\begin{array}{l}\text { Internal Municipal } \\
\text { Department }\end{array}$ & $\begin{array}{l}\text { External } \\
\text { Corporation }\end{array}$ \\
\cline { 2 - 3 } & 6 in total & 4 in total \\
\hline Municipal government & 6 & 4 \\
\hline Provincial government & 2 & 3 \\
\hline Operational (small business centre) & 4 & 4 \\
\hline Special projects - one-time funding & 3 & 4 \\
\hline Federal government - special projects & & \\
\hline Private sector & 2 & 1 \\
\hline Grants, special projects, and leveraged funds & 1 & - \\
\hline Partnership program & - & 1 \\
\hline Sponsorship & - & 2 \\
\hline Fee for service & & \\
\hline
\end{tabular}




\begin{tabular}{|l|c|c|}
\hline Universities, colleges \& other institutions & - & 1 \\
\hline Community Futures Development Corporation & 1 & - \\
\hline \multicolumn{2}{|l|}{ Note: This table does not claim to be an exhaustive and complete list. } \\
\hline
\end{tabular}

Sources: Participant interviews; budgets, strategies and annual reports of organizations

On average, external corporations accessed funds from a wider range of sources than internal departments (5.0 vs. 3.2 sources). Funding sources also varied with the mandate and size of organization. Of particular interest in service delivery model discussion is the potential for corporations to have greater access to external non-municipal funding sources. Therefore, an analysis is made of the participating organizations and their municipal and non-municipal funding.

Funding from municipal government forms the largest source of most economic development organization budgets. As shown in Error! Reference source not found., internal municipal departments received on average $83 \%$ of their total budget from municipal funding. The average for external corporations is $69 \%$, which increases to $80 \%$ when the outlying external organization in the ED $+\mathrm{SBC}+$ Tourism category is removed from the analysis.

Figure 3: Percent of total annual budget received from municipal sources

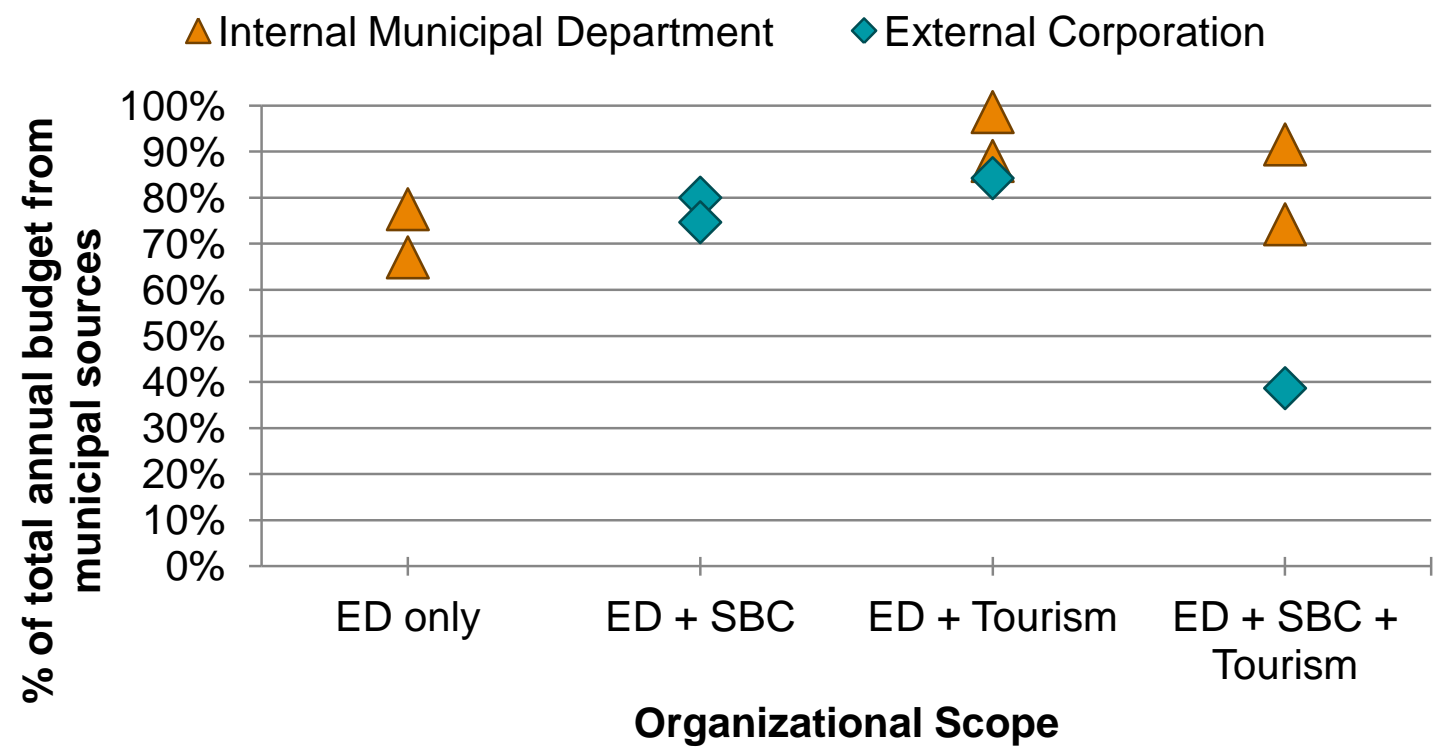

Sources: Participant interviews; budgets, strategies and annual reports of organizations

To compare the amount of municipal funding dollars received by participating organizations, the analysis was completed per capita to take the service delivery area population into account (Figure 4). The average municipal funding dollars per capita received by municipal departments is $\$ 13$. On average, external corporations receive $\$ 8$ municipal dollars per capita. When the outlying municipal department receiving over $\$ 25$ per capita is removed from the analysis, the 
average municipal dollars received by internal departments is $\$ 10$ per capita. Most organizations received municipal funding in the range of $\$ 4-15$ per capita.

Figure 4: Annual municipal funding dollars per capita by organizational scope

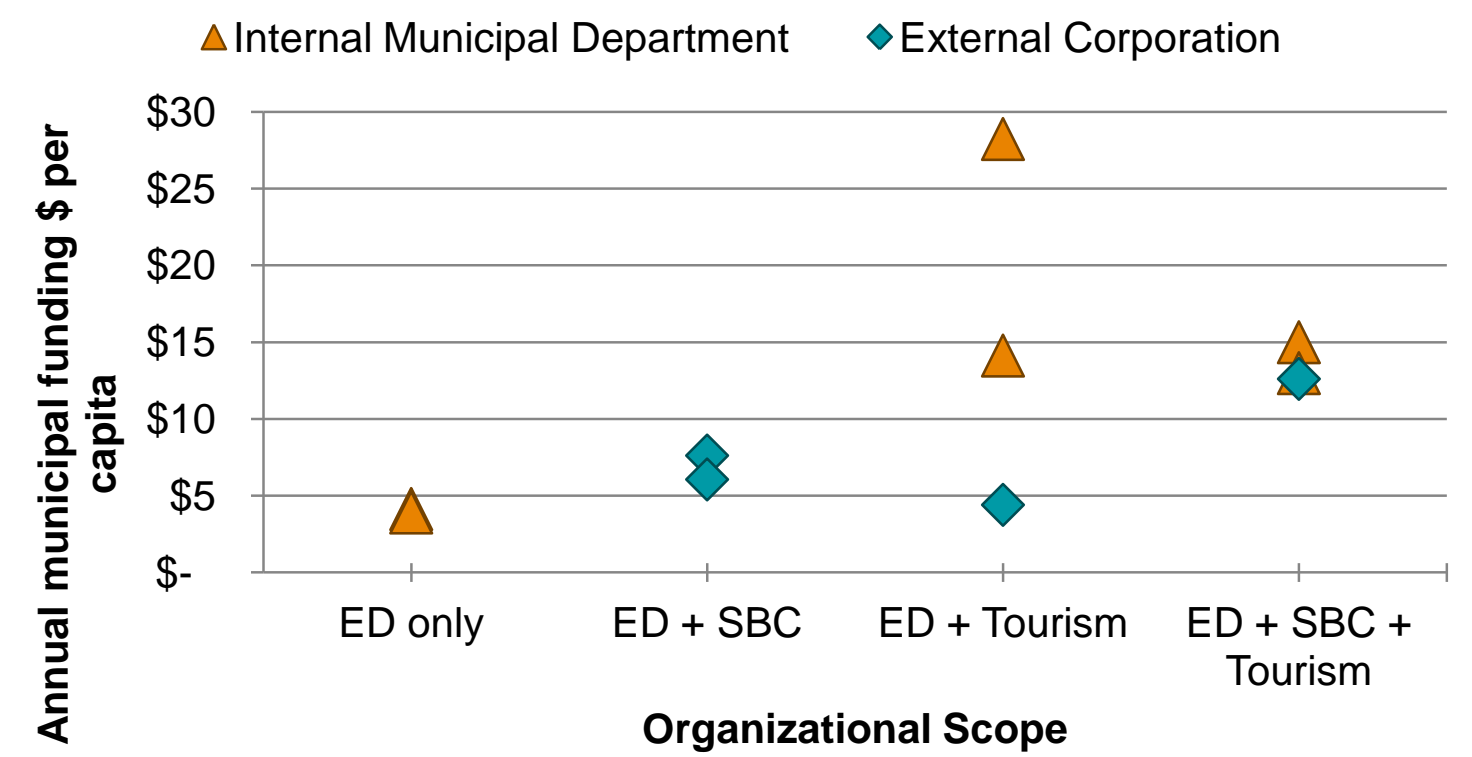

Sources: Participant interviews; budgets, strategies and annual reports of organizations; Statistics Canada, Census of Population, 2011 [Custom tabulations].

As shown in Table 4, funding for economic development organizations comes from a variety of sources beyond municipal government. Project budgets, which vary year to year, typically have greater non-municipal funds than core budget items. This makes it a challenge to measure nonmunicipal funding, as there is wide variation in project budgets. Many non-municipal funding opportunities are tied to expansion of scope and mandate. Thus, while additional external funds are an attractive proposition, they may come with additional expectations of and responsibilities for the organization. This is not necessarily a negative consequence if the expanded scope or responsibilities fit within the organization's goals. For example, one corporation received external funding dollars in exchange for their role in coordinating a community sustainability plan.

The same analysis of percentage of total budget and amount per capita was completed for nonmunicipal funding. In the analyses in Figure 5 and Figure 6, the impact of an extreme outlier on the small sample size is very evident, as it was in Error! Reference source not found.. The external corporation in the ED + SBC + Tourism category receives significant non-municipal funds through its research-innovation-commercialization centre function, producing the anomaly in the data and demonstrating the expanded operational scope often associated with additional funds. 
Figure 5 presents the other side of the equation of what was shown in Error! Reference source not found. Internal municipal departments received on average $17 \%$ of their total budget through non-municipal sources. The average for external corporations is $31 \%$. When the outlying external organization in the ED + SBC + Tourism category is removed from the analysis, this external average falls to $20 \%$.

\section{Figure 5: Percent of total annual budget received from non-municipal sources}

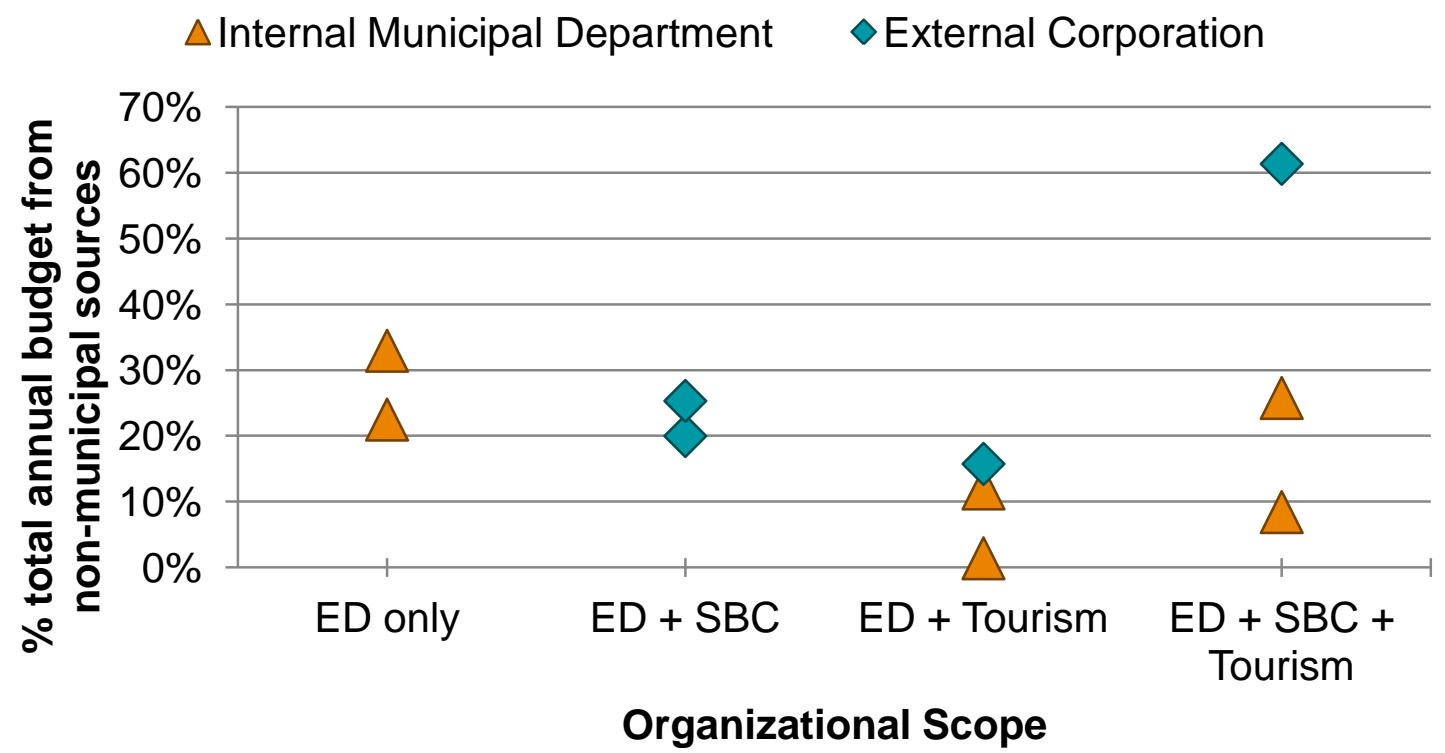

Sources: Participant interviews; budgets, strategies and annual reports of organizations.

On average, municipal departments receive $\$ 1.9$ per capita from non-municipal funding sources, as shown in Figure 6. The average for all external corporations is $\$ 6.2$, which falls to $\$ 1.6$ when the outlying external corporation in the $\mathrm{ED}+\mathrm{SBC}+$ Tourism category is removed.

Most of the organizations, including internal and external, indicated they have received some form of one-time funding from the provincial government such as the Rural Economic Development grant program. Five of the 10 organizations--two internal and three external-are also in receipt of operational funding for the Small Business Enterprise Centres.

The federal government was identified as a source of funding by three external agencies and two internal departments for special projects such as a foreign direct investment strategy or an export program. This suggests that corporations may have greater access to federal funding, a concept re-iterated by several participants, but there are opportunities for municipalities as well.

Both external and internal organizations are in receipt of private sector funding through a variety of means. One external organization receives approximately $4 \%$ of its annual budget through sponsorships. Another corporation mentioned cost-shared programs and projects with industry. 
The two other external agencies both expressed interest in increasing the share of funding received from the private sector. Arguably, the most formal private sector funding arrangement comes from an internal municipal department, which receives $11 \%$ of its total annual budget from local businesses that are members of a partnership program and pay an annual fee for services such as marketing.

Funding from universities and colleges was identified by the outlying external corporation in reference to its research-innovation-commercialization centre function. One internal department identified a Community Futures Development Corporation as a source of funding.

Figure 6: Annual non-municipal funding per capita by organizational scope

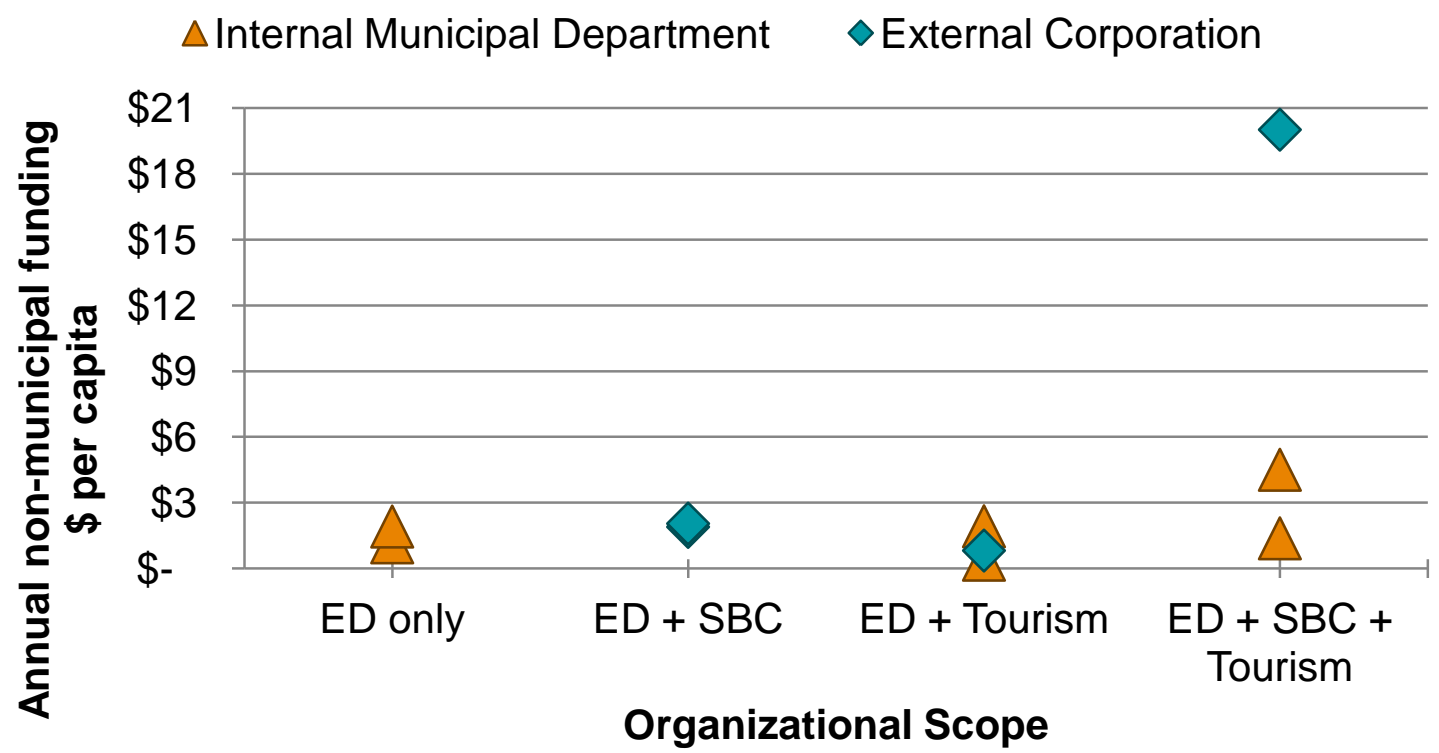

Sources: Participant interviews; budgets, strategies and annual reports of organizations; Statistics Canada, Census of Population, 2011 [Custom tabulations].

\subsubsection{Finances \& Service Delivery Models}

When asked whether they believe funding sources or the distribution of funding would change with an alternative model of service delivery, respondents expressed contradictory views. A range of strengths and weaknesses were stated for both models on budgets and other financial issues. 
Figure 7: Responses by service delivery model to the question "Would you expect your funding sources or the distribution to change if your organization were a different model?"
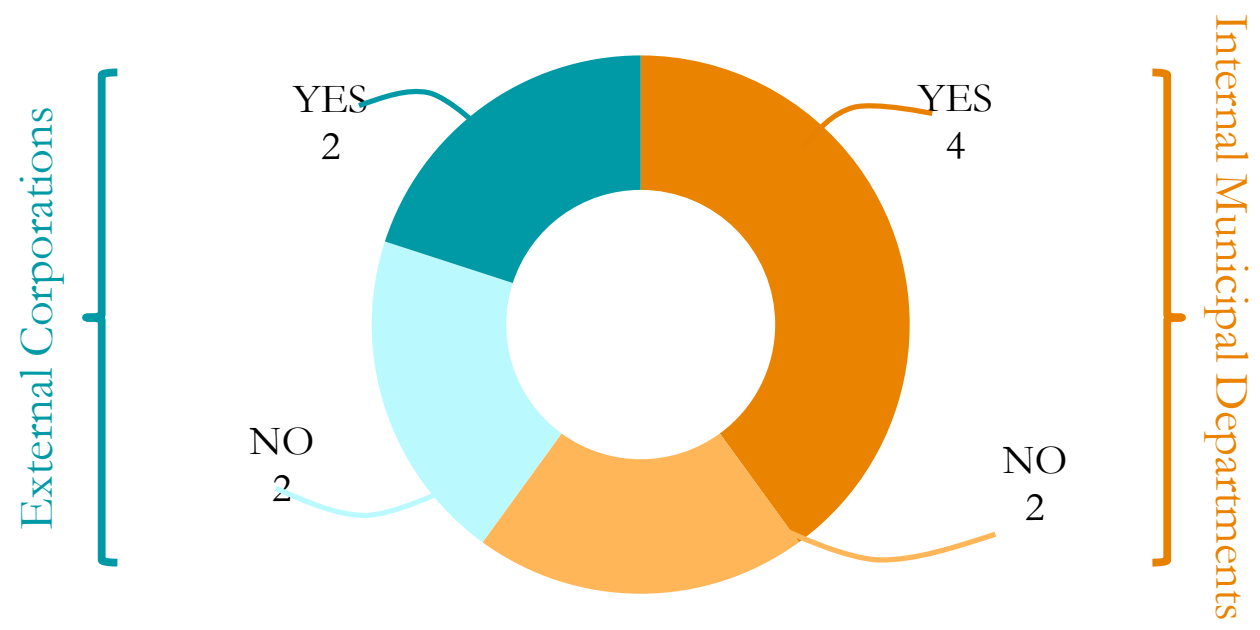

"If we were a municipal department we couldn't apply for special funding programs that municipalities wouldn't necessarily qualify for" (EDP 1).

The notion that non-profit corporations have greater access to external funding is recurring in the literature. All non-profit corporations interviewed identified this as a benefit to their structure while one municipal respondent identified it as a hindrance. Some of the corporations have been able to expand the scope of their work given this access to additional funding, as previously discussed. One municipal department mentioned this limitation but indicated they overcome the challenge by partnering with local non-profit organizations on projects involving this type of external funding. Municipal respondents also expressed concern that there is instability and an administrative cost to seeking external funds, such as time taken to prepare proposals and reports, and that the organization's original mandate and goals can be lost in an effort to please funders.

“We've always operated under the model that there's no free money out there and that we really have to be in charge of our own destinies. If you constantly keep looking for the funding, you're going to spend a lot of time looking and not a lot of finding” (EDP 2).

Turning to municipal sources, there were two main views on the stability of funding for service delivery models. While it was suggested that external corporations suffer from annual variation in budgets, two corporations that indicated they have multi-year funding agreements with their partner municipalities challenge this view. These agreements provide those corporations with financial stability over a longer planning period as opposed to annual budget cycles. Municipal officials suggested that their department transitioning to an external agency would likely result in a decrease in municipal funding as the move could be seen as a cost savings measure or Council would be unwilling to cede significant financial control. 
“This municipality has a philosophy that they've got to have some sort of say in what happens. They're not going to hand over that kind of money like that" (EDP 3).

Additional functions related to the distribution of finances were identified as a benefit of the external corporation. One participant indicated that their status as a not-for-profit corporation allows them to provide support to certain funding programs that would not be possible in a municipality. For example, the corporation acts as the third party validator for an Ontario Works employment program that provides funds to companies for hiring.

"We provide third party support. Our structure allows us to be a flow-through agency for special projects because we are autonomous" (EDP 4).

There were opposing views as to how operational costs might differ between internal and external organizations. One participant suggested external agencies have higher costs: "If we were a separate corporation we might have to pay rent, or for computers, or for IT services, or for banking and audit fees" (EDP 5). However, it was suggested by two participants (as fact by an external participant and as perception by a municipal participant) that a corporation can be structured to run on a more cost competitive basis than a municipal organization.

\subsection{Partnerships \& collaboration}

"Communication and working together are critical to the success of the majority of economic development endeavours" (EDP 6).

There was general agreement by respondents in the study that the types of partnerships and relationships formed by organizations differ between service delivery models. One municipal participant disagreed: "Having worked in a couple of different models, I would have to say that they wouldn't differ significantly" (EDP 7).

When asked to identify some key partnerships, respondents identified a wide variety of organizations and groups (Table 5). Municipal departments were more likely to identify some form of regional collaboration such as involvement in regional sector-based initiatives (e.g., the Ontario's South Coast tourism brand) or membership in regional economic development organizations (e.g., South Central Ontario Region Economic Development Corporation, Southwest Economic Alliance, Regional Tourism Organizations). It is worth noting, however, that the multi-jurisdictional nature of all four external corporations implies that these organizations are, themselves, a form of regional collaboration among partner single, upper, and/or lower tier municipalities. 
Figure 8: Responses by service delivery model to the question "Would any of your key partnerships differ if your organization followed a different model of service delivery?"

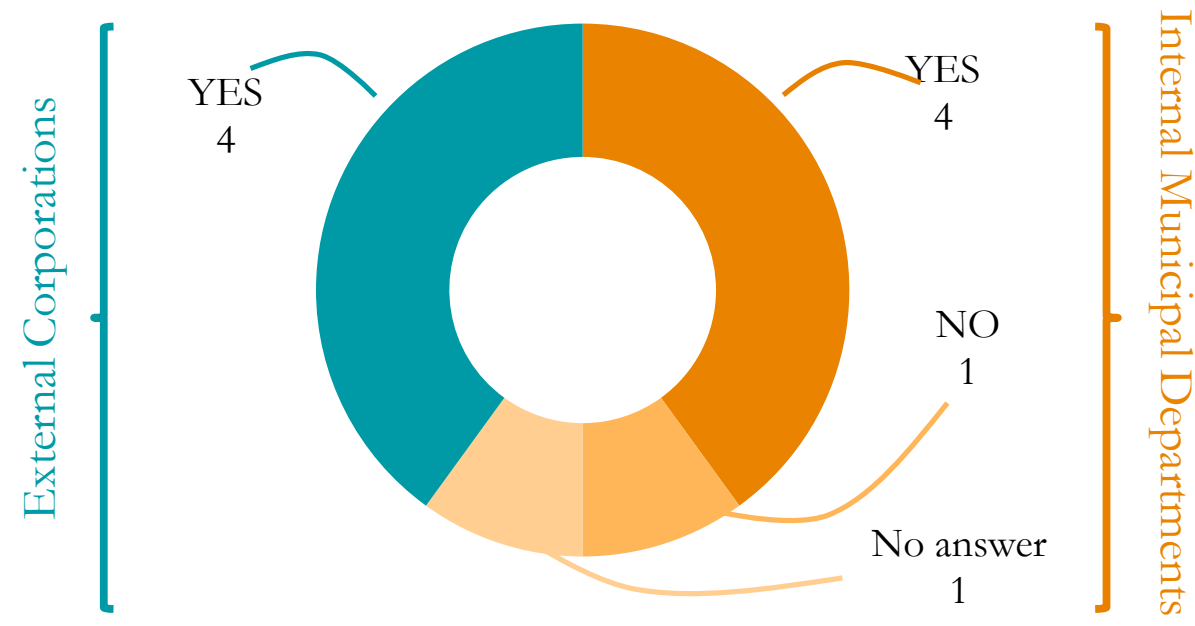

Table 5: Sample of key partnerships identified

\begin{tabular}{|l|c|c|}
\hline Types of Partners & $\begin{array}{l}\text { Internal } \\
\text { Municipal } \\
\text { Department }\end{array}$ & $\begin{array}{l}\text { External } \\
\text { Corporation }\end{array}$ \\
\cline { 2 - 3 } & 6 in total & 4 in total \\
\hline BIAs and Chambers of Commerce & 4 & 1 \\
\hline Sector-based associations and initiatives & 4 & 4 \\
\hline Businesses & 1 & 2 \\
\hline Regional projects and initiatives $($ e.g., south coast tourism) & 3 & 1 \\
\hline Regional organizations $($ e.g., SCOR, SWEA, RTOs) & 3 & - \\
\hline Educational institutions & 1 & 2 \\
\hline Community Futures Development Corporations & 4 & - \\
\hline Workforce, immigration, and similar boards & 1 & 2 \\
\hline Provincial government $(e . g .$, OMAFRA, MEDI) & 3 & - \\
\hline Federal government $(e . g .$, FedDev, Parks, consulate offices $)$ & 3 & - \\
\hline $\begin{array}{l}\text { Note: This table is not an exhaustive and complete list of partners affiliated with the } \\
\text { participating organizations. }\end{array}$ & \multicolumn{2}{|l}{} \\
\hline
\end{tabular}

Source: Participant interviews.

Other levels of government and Community Futures Development Corporations (CFDCs) were identified as key partners only by municipal departments. Corporations did not list these organizations as key partners, although other levels of government were identified with regards to other topics such as funding.

All organizations identified private sector relationships as key partnerships. More municipal departments listed business associations, but fewer identified businesses in general and 
workforce or immigration boards. All corporations noted partnerships with sector-based associations and initiatives while four of the six municipalities identified such relationships.

"We work as close as we can with the BIAs and Chambers so that we can keep the pulse of the business community... It's like having an extra ec dev officer without having to pay for it" (EDP 8).

While some differences are observed in the list of partnerships named by the organizations, the most frequent difference identified between the internal and external model is municipal relationships. This refers to both relationships between the economic development office and (other) municipal departments as well as collaboration among several municipalities in a region.

"You may not have the same rapport... the ability to just have those informal conversations that sometimes solve the problems and get things moving ahead. I think that would be more limited [in a separate agency], for sure" (EDP 9).

Four of the six municipal departments indicated that their relationships with other departments in the municipality would suffer if they became a separate external corporation. The placement of these economic development departments as internal offices of the municipality has several advantages. These offices benefit from improved informal relationships and familiarity with the other departments and key decision-makers. Their existence within the same chain of command can lead to more cohesive planning and duplication. They are better equipped to be a "one stop shop" for businesses to access all municipal services.

Questions were raised by one municipal official about whether these strong internal relationships are necessary for the goals of the economic development office. None of the external corporations identified their relationships (or lack thereof) with partner municipalities as a hindrance and some indicated their access to key municipal actors is quite straightforward. One respondent identified an absence of cooperation between the municipalities and the corporation in the past. This organization has since taken a proactive role in working with the municipality:

"We've now begun quarterly meetings and dialogue to open up communications and share issues, challenges, and opportunities. That's further extended itself into us having a role and added funds to assist in [a specific project]. That's an example of growing partnership and practicality. They've increased the budget, given us a role, and have an expectation for us to deliver" (EDP 10).

Finally, it was noted that relationships with and between multiple municipalities in a region can be strengthened through a multi-jurisdictional corporation that encourages communication and collaboration as opposed to individual municipal economic development departments. 


\subsection{Organizational structure \& governance}

\subsubsection{Governance structure}

One of the key differences between internal municipal departments and external corporations is their governance structure. Three types of structures were identified in this study. Municipal departments each report to a single municipal council and are sometimes supported by an Advisory Board or Committee. All of the external corporations in this study are governed by a Board of Directors.

\section{Figure 9: Governance structures of interviewed organizations}

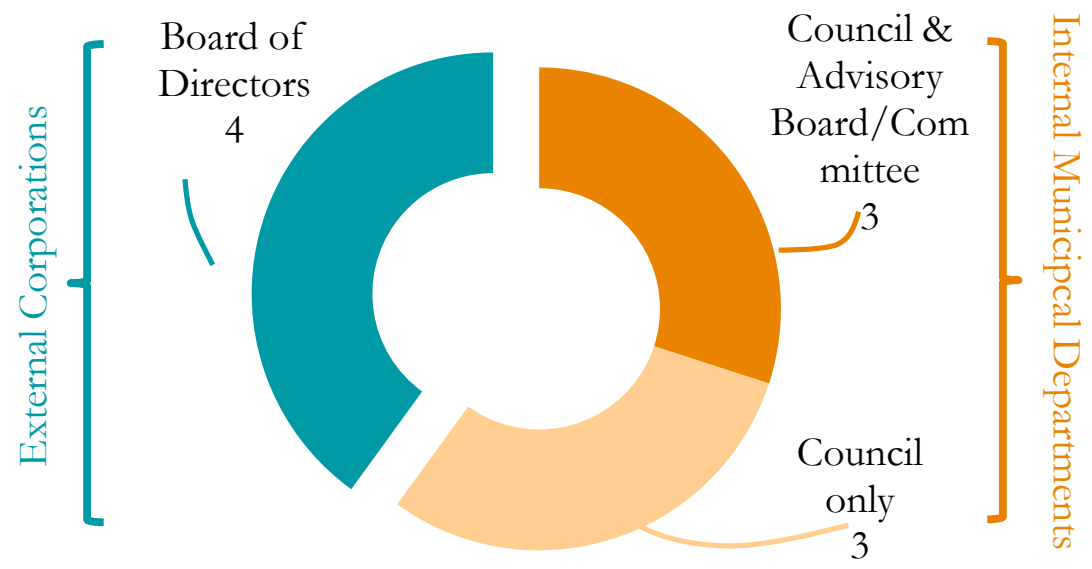

\section{Council Only}

"These people know their communities... they're well connected...[but] they aren't experts in economic development... decisions are more politically based, maybe, than industry informed" (EDP 11).

Three of the municipal departments interviewed have only municipal council in place as a governing body. In one case, there is an Economic Development Committee of Council that meets with the economic development practitioner on a more frequent basis than full council meetings. The benefits of council as the governing body approach include the network access provided by the well-connected councillors and the broader (regional or county-wide) understanding of economic development gained by the councillors. Weaknesses in this structure include a potentially weaker connection to industry.

Council and Advisory Board / Committee

"It's very important to have them in place because we use them as a barometer-someone to bounce ideas off of to make sure that we're still going in the right direction" (EDP 12). 
Three of the municipal departments interviewed have, in addition to municipal councils, advisory committee(s) generally comprising private sector representatives with council liaison members. These committees do not have any formal financial or decision-making responsibility. However, they play essential roles in policy change, advocacy, strategizing, and providing connections to industry and advice based on on-the-ground experience. This structure is challenged, however, by the potential for conflict between the views of the Committee and Council. This additional layer of governance can also create an extra administrative burden to the department, taking time from other priorities.

\section{Board of Directors}

"The Board of Directors exists as the face of the organization... it includes a mix of individuals that present different thought processes and provide an interactive decision-making environment" (EDP 13).

The Boards of Directors of the external corporations interviewed vary in composition. Members include large and small business owners in various sectors, industry association representatives, and education, labour, and municipal partners. The corporations interviewed frequently identified their strong, dedicated, volunteer board as a key factor of success for their organizations. Several also noted that forming a board with good representation from different parts of the region, sectors, gender, ethnicities, and between urban and rural areas can be an onerous task.

\subsubsection{Governance Challenges}

A frequent argument for the use of corporations over municipal departments is increased private sector alignment. The internal departments with advisory committees demonstrate that business involvement in municipal economic development practice is also possible. One of these departments also hosts annual focus groups and symposiums to engage additional private sector partners in networking, idea generation, and providing direction to move forward. Private sector influence in the internal model is structurally limited however, as the ultimate financial and decision-making authority lies with council.

“...it's important to keep the politics out of the business side of the organization... It's important for people running economic development offices to make sure that their board is truly focused on strategy and fiduciary responsibility and not engaged in the day-to-day running of the operation because that's where a lot gets in trouble"(EDP 14).

A challenge raised by several participants in both models is the involvement (or "meddling") of governing bodies in the operations and management of the organization. This appears to be an issue with councils, advisory committees, and boards regardless of the governance structure. In the case of council, it is much easier for councillors to engage in the operational matters of an in- 
house municipal department than an arm's length organization; thus, an external agency can provide a buffer from political "meddling" in the office's operations. An arm's length corporation, however, can also face the challenge of a board learning how to govern rather than manage. Participants indicated that this issue could be resolved through clarification of roles, responsibilities and expectations.

One external corporation representative identified political representation on the board as a hindrance to the organization. All of the municipal advisory committees have elected official liaison members that act as a link to council. Of the four boards of directors, three have elected official representation from their municipal funding bodies. The fourth board had elected official members replaced with the CAOs of the municipalities when other board members felt the political participation "diluted focus from pure economic development to [politics]" (EDP 15).

\subsubsection{Confidentiality Issues}

When asked whether confidentiality problems arise within their current governance structure, only two of the 10 organizations-both internal municipal departments-identified such challenges, with one organization indicating it is a major problem. Most respondents suggested that there is often much interest and pressure from stakeholders, such as the mayor and council, to be "in the know." However, participants in both models indicated that they are able to manage sensitive information and explain to stakeholders why certain information must remain confidential. It would appear that confidentiality issues are not related to service delivery models. There were contradictory opinions on how confidentiality issues would change when going from an internal municipal model to an external model. One participant from a municipality suggested that the bureaucracy of the municipality leads to the premature involvement of council and other departments in any given project, thus creating confidentiality issues that would otherwise not exist. Another municipal participant suggested that creating an external corporation would lead to confidentiality issues "because then you would have a separate group that's reporting to another authority [like a Board of Directors], having to interact with a group that's reporting to this authority [council]" (EDP 16). This interaction of two groups existing under separate lines of command has the potential to create confidentiality problems as well as other communication challenges. However, in practice, confidentiality issues seem to be well managed and rarely reported as a problem.

\subsubsection{Organizational Resources \& Structure}

\section{Staffing}

Two approaches were taken to determine the staffing resources of the municipalities. The first considers only permanent employees within the economic development department, from the department director or manager down to permanent staff level. The second approach includes staff within the economic development department as well as senior municipal management 
(such as Chief Administrative Officers and General Managers) engaged in economic development activities and linking the department to council. For external corporations, the number of permanent employees from CEO or President down to officer-level staff was considered. These figures do not include any contract or seasonal staff due to the variation in temporary staffing needs over time. For some organizations, particularly those engaged in tourism and running visitor information centres, contract and seasonal employees can figure largely into their overall staffing plans.

Table 6: Minimum, average, and maximum number of permanent employees by model

\begin{tabular}{|l|l|l|l|l|}
\hline & \multicolumn{3}{|l|}{$\begin{array}{l}\text { Number of permanent } \\
\text { employees }\end{array}$} & $\begin{array}{l}\text { Average } \\
\text { population } \\
\end{array}$ \\
\cline { 2 - 5 } & Minimum & Average & Maximum & 2011 \\
\hline Internal Municipal Department & 1 & 5 & 10 & 61,509 \\
\hline $\begin{array}{l}\text { Internal Municipal Department \& Senior } \\
\text { Municipal Management }\end{array}$ & 2 & 6.5 & 12 & 61,509 \\
\hline External Corporation & 11 & 14 & 17 & 270,315 \\
\hline
\end{tabular}

Source: Participant interviews; organization websites and reports

There are notable differences between the staffing resources available to organizations of each model in the study. These differences are likely the result of variation in service area size and are not necessarily attributable to the model type. The external corporations in the study cover significantly larger service areas. Additional analysis was completed to compare the number of employees to population size (Figure 9). This figure shows that there is no clear pattern of one service delivery model having access to more staffing resources. Perhaps not surprisingly, the similarity between this figure and Error! Reference source not found. showing annual core operating budget is striking. 
Figure 9: Number of permanent staff per 10,000 population by service delivery model and organizational scope.

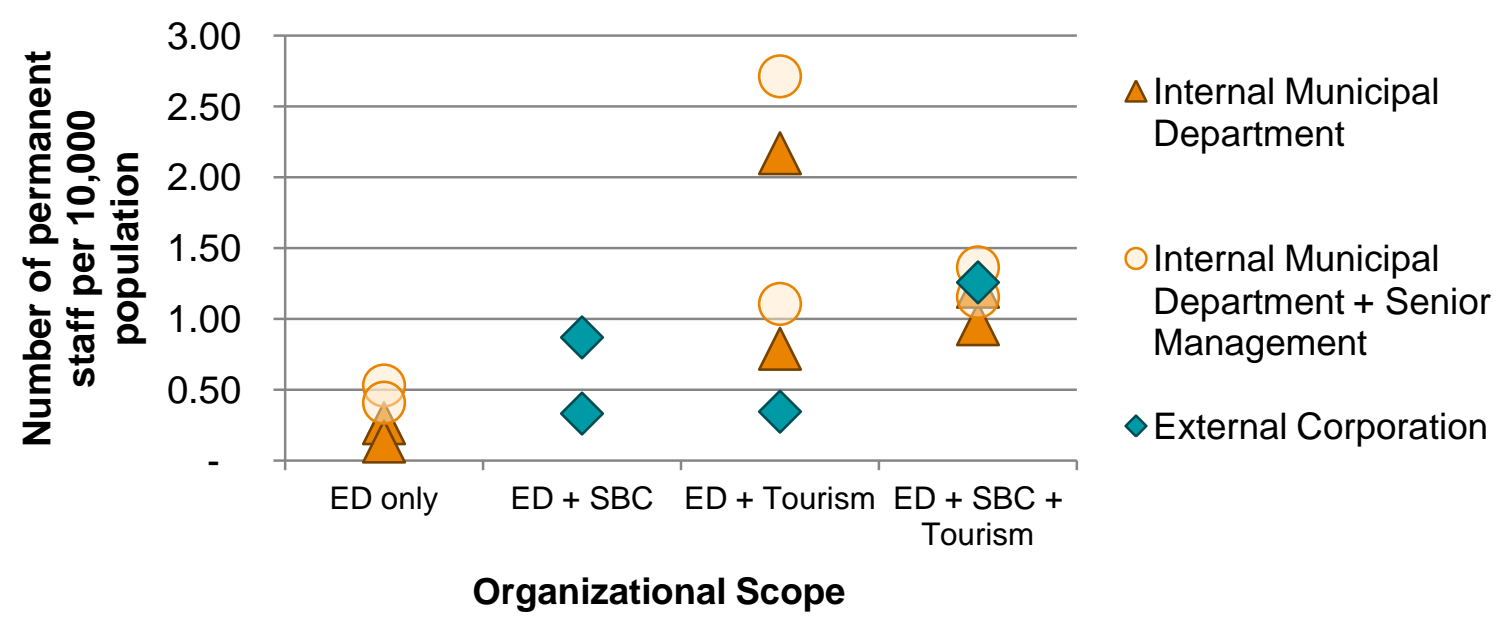

Source: Participant interviews; organization websites and reports; Statistics Canada, Census of Population, 2011 [Custom tabulations].

Four municipal respondents and two external respondents identified, unprompted, that their professional, dedicated, and committed staff are one of the key factors behind their organizations' successes.

Hierarchy

The organizational structure was also analyzed from the perspective of hierarchical layers. In examining the number of levels in the organizational structure from the governing body (i.e., Board of Directors or Council) down to the staff, there does not appear to be any significant difference between municipal departments and external corporations (Table 7).

Table 7: Minimum, average, and maximum number of levels in organizational hierarchy from governing body to staff.

\begin{tabular}{|l|l|l|l|}
\hline \multirow{2}{*}{} & \multicolumn{3}{|l|}{ Number of levels in hierarchy } \\
\cline { 2 - 4 } & Minimum & Average & Maximum \\
\hline Internal Municipal Departments & 3 & 4.3 & 6 \\
\hline External Corporations & 3 & 4.3 & 5 \\
\hline
\end{tabular}

Source: Participant interviews; organization websites and reports.

There may be differences, however, in the decision-making authority at the different hierarchical levels in the two models. Two municipal departments expressed concerns that their municipal departments are at the lower level of the overall municipal organizational chart. One recognized that there are "layers of authority" in the organization and the formal structure does not always apply in practice. The lack of perceived authority was also raised as an issue: 
"The other clear thing I find missing-because I've worked in both-is the perceived authority. When I was at [a corporation], I would make decisions and the organization would stand behind those decisions. I had the authority to do it and I would do it. That impresses clients. They're dealing with a decision-maker. What they're dealing with here in our organization is somebody who can't make decisions. Council has to make all decisions in a municipality...that's a significant problem in dealing with potential investors" (EDP 17).

Additional discussion of decision-making authority can be found in the next section.

4.5 Process, decision-making \& accountability

Internal Municipal Departments: Contrasting Views

"Our council procedures require written reports; all reports must be finalized 10 days before the council meeting; no items can be added to the agenda within 10 days prior to the meeting" (EDP 18).

Respondents from both models indicated that internal municipal departments are more bureaucratic and have more formal procedures and layers, resulting in slower processes and longer timelines. The high number of requirements in the process and timelines is most evident for any decision to be made by council. Challenges also arise from reporting through senior management who may not have a strong understanding of economic development.

"Decision making is pretty fast on daily issues. I would need approval for large expenditures, controversial issues, and major projects. Otherwise I make the decision (perhaps with my CAO) right at the time of the request" (EDP 1).

These "cumbersome" internal checks and balances are a particular concern if "everything has to go to council," as suggested by one respondent from a corporation. There were, however, contrasting views on the level of decision-making authority in municipal departments. Some municipal respondents indicated that there are decisions that can be made without requiring a high level of approval and are, therefore, dependent on the individuals involved and not on formal processes. The detailed types of decisions that fall into different levels of decisionmaking authority, their frequency and consequent impact on program goals were not discussed due to time constraints. The two municipal respondents who report directly to the CAO identified the benefits of this structure, such as having a seat at the decision-making table and approaching other departments on a peer-to-peer basis.

"Moving at the speed of business, business doesn't have time. There is a process and that's the perception... and then there's the reality. My access to council has been reasonable, I would say. I've never waited" (EDP 20). 
Considering decisions that require a high level of decision-making authority, respondents indicated that individuals could respectfully bypass formal municipal procedures and expedite the process, particularly when critical decisions are involved. In some cases, this may require an individual to go directly to the mayor and council. The perception is that many formal procedures and regulations that may hinder decision-making exist in a municipal environment. In practice, informal processes can lead to faster decisions. One municipal official with experience in both models suggests the municipal model has faster timelines overall given the stronger internal relationships and seamless access to key decision-makers and lead senior staff.

External Corporations: Speed and Flexibility

"We're definitely more nimble and quicker and less restricted than the local government. It has a positive impact on timelines" (EDP 21).

All participants from external corporations stated that their model of service delivery allows for faster, more creative, proactive, and nimble decision-making when compared to the more bureaucratic and structured municipalities.

"If we did need to pull together our Board for a decision, they're pretty responsive and we can do it either by email or a quick meeting” (EDP 22).

One explanation for the improved timelines is greater flexibility in the decision-making process. With less stringent requirements and procedures to adhere to, such as specified timelines of when and how agendas must be submitted and meetings scheduled, faster decisions can be made in the external model.

“In terms of responding to projects, we just do it. We don't need to take projects to the Board for review unless we were trying to put a major incentive package on the table or something that required some special consideration" (EDP 23).

Participants suggested that processes are faster in external corporations due to different levels of decision-making authority. Respondents indicated that more decisions are made by corporation staff instead of moving up to the Board of Directors. With "people on the front line with the authority to make the decision," as one municipal official describes, fewer decision-makers need to be involved, less communication is required, and timelines are shorter.

Factors Beyond the Model

While discussion around the speed and flexibility of processes is highly tied to the service delivery model, participants highlighted several factors affecting decision-making that exist outside of the model and structure. 
The size of the organization is a major factor in how quickly processes and decisions can be executed. Smaller organizations are likely to have fewer levels of hierarchy and fewer procedures, resulting in faster decision-making. One municipal official with experience in one large and one small municipality suggests that while they are both internal departments, the organizations and their functioning are very different primarily due to the difference in size and volume of activity.

It was also suggested that municipal status plays a role in how economic development services are delivered. The status of the municipality or municipalities included in the organization's service delivery area influences the functions and responsibilities of the organization and the types of decisions that need to be made. For example, an upper tier municipality supporting lower tier municipalities that provide their own on-the-ground economic development services is more likely to be a facilitator and networker and thus less likely to require large decisions to be made through council.

The issue of decision-making authority is most relevant in determining how and how quickly decisions can be made and has been discussed in relation to both models. It is worth noting, however, that where the decision-making power lies may negate any processes internal to economic development organizations. There are some decisions, such as re-zoning or grant applications, that ultimately lie with council, other levels of government, or external agencies. Economic development organizations in both models are subject to the same timelines.

Accountability versus speed

"Accountability is the single biggest issue facing economic and community development agencies, whatever form they are” (EDP 25).

Several participants in both service delivery models identified accountability as an essential consideration in the practice of economic development. There are differences by service delivery model in how this issue is perceived.

The issue of accountability was primarily raised relative to speed of decision-making with participants suggesting that speed and flexibility may be counter to accountability and transparency. 


\section{Speed \& Flexibility}

"The arm's length model

allows [our corporation] to be

nimble and to operate

independent of the grind of a

municipal organization. If

this privilege is abused, it

becomes a problem" (EDP

26).
"The reason that council

meetings are consistently

on the same day is so that

they're accessible and

open to the public...so

that they can speak to

issues" (EDP 27).

Accountability \& Transparency

Municipalities are generally seen as more accountable than separate corporations. The perception of increased accountability in the municipal model is cited as "a big factor in [one corporation's] transition to [an] internal department" (EDP 28). Three of the six municipal departments indicated that transitioning to the external model would decrease the organization's accountability, although opinions were mixed on whether this would be an overall positive or negative change. In the words of one municipal official,

"The [external model] is unregulated. It wouldn't be driven by the Municipal Act. There are certain things you would be able to do that would give you more flexibility, for sure. But maybe sometimes you need somebody looking over your shoulder - just a little reminder to keep it between the lines. There's got to be respect out there for the profession. If all it is is who can strike the most crooked deal to get the job done, is that right? I guess there are pros and cons" (EDP 29).

This sentiment that accountability is necessary to earn the respect, trust, and support of stakeholders was echoed by others.

\section{Performance Measurement}

Participants from external corporations also recognize the need to address accountability issues. Notably, two respondents emphasized the connection between accountability and performance measurement and reporting. They also suggested that performance measurement needs and issues should not differ between internal and external models; thus, they did not see any major difference in how organizations of both models would demonstrate accountability. One participant describes the challenge: 
"It's fine to say that we're accountable and to do reports but if your stakeholders are trying to measure you on different things, that becomes a challenge. That's where it's different than corporate. You're talking about helping to create community capacity. We know what it means but how do you measure that? How do you measure relationships with the university? How do you measure the impact of regional collaboration [or] marketing your region? And that's the same everywhere. It's why so many people leave this industry every year" (EDP 30).

This study attempted to measure differences in performance between the two models but encountered two problems. The first is attribution. There are flaws in attributing progress in a local economy to a particular organization, let alone to its service delivery model. The second is inconsistency in the use of indicators. In the field of economic development, there are no universal standards for key performance indicators or data sources although professional associations such as the Economic Developers Association of Canada and Economic Development Council of Ontario are encouraging the use of these indicators. Responses from participants in this study indicated that external corporations had performance indicators more readily available.

\section{Openness and Transparency}

Given the nature of accountability, measurement is a challenge. One approach to assessing accountability is evaluating the openness of an organization and its willingness to share information. An analysis of information freely available and accessible on the participating organizations' websites was completed and is summarized in Table 8.

All organizations are open about finance-related documents, although some of the budgets shared on corporation websites are not the most current. Municipalities provide up-to-date finance information, since budgets are prepared annually, and council meeting minutes were found on all municipal websites. While available, this information is less accessible given that the economic development office is just one department within the municipality. For example, budget information is typically buried on the finance office webpage and may not be easily accessible from the economic development office webpage.

The area where corporations are strong is the provision of formal annual reports. No municipal department had annual reports available, although three issue regular quarterly newsletters that provide similar information (recent activities, budget and staffing updates). It is also possible that similar information is provided for municipal departments through larger documents covering the entire municipality or in council meetings as documented in meeting minutes. Nevertheless, a formal annual summary is easier to access on external corporation websites. Thus, while municipalities have accountability "built in" to their regulated processes, corporations take additional steps to demonstrate their accountability through actions such as annual reporting. 
Table 8: Information available on organization websites by model.

\begin{tabular}{|l|l|l|}
\hline Information Types & $\begin{array}{l}\text { Internal } \\
\text { Municipal } \\
\text { Department }\end{array}$ & $\begin{array}{l}\text { External } \\
\text { Corporation }\end{array}$ \\
\cline { 2 - 3 } & 6 in total & 4 in total \\
\hline Financial statements and/or budgets & 6 & 4 \\
\hline Meeting minutes (for council, committee, or board) & 6 & 1 \\
\hline Strategy or strategic plan & 4 & 3 \\
\hline Formal annual report & 0 & 3 \\
\hline Regular newsletter (updated within last 6 months) & 3 & 2 \\
\hline Social media updates, blog, links to news stories & 6 & 4 \\
\hline
\end{tabular}

Source: Participant interviews; organization websites and reports

\section{Conclusions}

Does the service delivery model matter?

Most of the study participants have experience with various organizations in both models, as well as business and other government organizations. All participants believe that the service delivery model makes a difference in some areas of operation, but there are contradictory views on which areas are affected and which model is superior in each of the areas. Analysis of the functions and financial resources shows substantial overlap between internal and external organizations. Key findings are reported for each topic below:

- Organizational Scope: There is variety in the mandate and functional program areas of the organizations interviewed. Three functions are identified as most likely to affect operational areas such as budget: tourism, small business and entrepreneurship, and innovation and knowledge economy programs. Organizations in both models provide these functions.

- Finances: The average total budget per capita was nearly equal between internal and external organizations while internal organizations had higher average operational budget per capita. External organizations had a greater proportion of their total budget funded by non-municipal "outside" sources and identified a greater variety of funding sources.

- Partnerships: Respondents from both types of organizations stated that the service delivery model affected partnerships and that both types of organizations had many partnerships. Overall, municipal departments identified more partnership types than external corporations. The most cited difference between the internal and external model was relationships between the economic development office and other municipal departments. 
- Governance: Three governance models were identified in the study - council only and council with advisory committee for internal departments and board of directors for external corporations. Private sector involvement was demonstrated in both models, but financial and decision-making authority ultimately lies with council in the municipal model.

- Organizational Structure: There were no notable differences between staffing resources or levels of hierarchy between the models. However, external corporation staff are reported to have greater decision-making authority than municipal staff.

- Decision-making: The study attempted to empirically measure average decision-making timelines in each model, but this was not possible. The general opinion was that external corporations have faster and more flexible processes and timelines. There were contrasting views on the speed of the municipal model due to strong internal relationships, access to decision-makers, and faster than perceived informal processes.

- Accountability: Respondents indicated that there is tension between speed of decisionmaking and accountability. There was agreement that municipalities are highly accountable given their formal processes. Corporations have taken steps to demonstrate accountability through performance measurement and public reporting.

Are other factors more influential than the model?

When discussing decision-making timelines, participants indicated there are other factors beyond the model that influence speed such as the size of the organization or where the decision-making power lies for the given situation. Speaking more generally, one participant suggested that both the internal and external model can function well depending on the leadership and skills of the organization's staff:

"It's really a management and communications issue. It depends on the capability of who is leading the economic development organization, the capabilities and understanding of the mayor and council. There are well run successful public-private partnerships and there are well run municipal operations. A lot depends on history and who the actors are" (EDP 32).

Another participant indicated that the effort and dedication of individuals can have a greater influence on the organization and its community's economic future than the organizational model: "Flipping the switch and going to a different model isn't going to change the economic reality inside of our community. Hard work changes that, not models" (EDP 33). In short, leadership and people matter.

Service delivery models: "it needs to reflect the community" 
Participants suggested that the debate about service delivery models is ongoing:

"Even in areas that look like they're doing really well, there's always going to be those on council that will ask if we should be doing it another way...Either one can work, but the reality is it's always going to be a question as to which is the better model" (EDP 34).

Several respondents said that the issue has been discussed in their communities on several occasions.

The purpose of this study was to analyze and compare the internal municipal and external corporation models of service delivery. While there are many opinions about differences between the models, some of those opinions are contradictory. Analysis suggests that differences exist, but in practice, the range of financial and staffing resources and functions found in the organizations overlap. Neither model is identified as superior. The two structures differ and each community should consider which model fits its people and partners best.

For economic development organizations considering a new model, the words of one participant emphasize the importance of taking context into account and choosing a model that is appropriate for the situation and circumstances:

"It really needs to reflect the community, the aspirations of the community, the culture... the key is to stay connected so that you are delivering a service that they need and in a way that they want it. I think both the stand-alone and the department can work equally well in other scenarios. It's about how you're engaged with the stakeholders in the community" (EDP 35).

\section{About the Authors}

Paul Parker is the Director of the Economic Development Program and a professor at the University of Waterloo. His research focuses on building sustainable communities by creating win-win opportunities for the environment and economy. He is particularly concerned with how local economic development strategies can achieve a sustainable future. Sustainable energy systems are an essential starting point, so he looks first at conservation and improving energy efficiency, then at renewable energy sources and smart grid networks as integral parts of community energy plans. Paul combines his strong research background with direct experience engaging local representatives from communities across Canada and overseas to envision and build local capacity, vitality and sustainability.

Evonne Donaher is Energy Services Coordinator at REEP Green Solutions, an environmental non-profit organization. Prior to this, she was a Commercialization Analyst at the Federal Economic Development Agency for Southern Ontario, a Community Economic Development Research Advisor at the Ontario Ministry of Agriculture, Food and Rural Affairs, and a Program 
Assistant in the Climate Change Impacts and Adaptation Division of Natural Resources Canada. She holds a Master's of Applied Environmental Studies (MAES) in Local Economic Development (LED) from the University of Waterloo. She has completed research related to economic development service delivery, local food systems, and green building.

\section{References}

Blais, P., \& Redden, A. (2009, February). Investing in economic development: Important key indicators municipalities should assess. Municipal World, 19-21.

Blakely, E., \& Leigh, N. G. (2009). Planning local economic development: Theory and practice (4, illustrated ed.) Thousand Oaks, California: SAGE Publications.

Bowen, W. M., Rubin, H. J., \& Hill, E. W. (1991). Management of economic development. In Managing local government: Public administration in practice. Newbury Park, CA: Sage Publications.

Douglas, D. J. A., \& Chadwick, S. J. (2003). Toward more effective rural economic development in Ontario. Guelph: School of Environmental Design and Rural Development.

Myhal, N. (1994). Existing Rationales for Agencies, Boards and Commissions. In D. Richmond \& D. Siegel (Eds.), Agencies, boards, and commissions in Canadian local government (pp. 3748). Toronto, ON: The Institute of Public Administration of Canada.

Redden, A. (2010). Is there a best practice? A better understanding of local economic development in rural Ontario. Papers in Canadian Economic Development, 12, 30-57.

Richmond, D. \& Siegel, D. (1994). Conclusion and a look to the future. In D. Richmond \& D. Siegel (Eds.), Agencies, boards, and commissions in Canadian local government (pp. 111-116). Toronto, ON: The Institute of Public Administration of Canada.

Rubin, H. J. (1986). Local economic development organizations and the activities of small cities in encouraging economic growth. Policy Studies Journal, 14(3), 363-388.

Rubin, H. J. (1988). Shoot anything that flies; claim anything that falls: Conversations with economic development practitioners. Economic Development Quarterly, 2(3), 236-251. doi:10.1177/089124248800200304

Siegel, D. (1994). The appropriate use of agencies, boards, and commissions. In D. Richmond \& D. Siegel (Eds.), Agencies, boards, and commissions in Canadian local government (pp. 83110). Toronto, ON: The Institute of Public Administration of Canada. 
Thompson, S. (2010). Delivery models of local economic development: An analysis of internal and external models in Ontario. Papers in Canadian Economic Development, 12, 86-110.

Union of British Columbia Municipalities (UBCM). (2010). Evaluating the economic development role of BC local governments: A snapshot of community effort and opportunity. Union of British Columbia Municipalities. 